\title{
IATROGENIC ('CLINICIAN-INDUCED') DAMAGE INCURRED BY HUMAN SPERM DURING INFERTILITY TREATMENT: POSTGRADUATE RESEARCH AND COLLABORATIVE DEVELOPMENTS BETWEEN THE UNIVERSITIES OF MALAYA AND OXFORD
}

\section{Yelumalai S, Jones $C$, and Coward $K$}

Nuffield Department of Obstetrics and Gynaecology, John Radcliffe Hospital, Oxford

\section{Correspondence:}

Nuffield Department of Obstetrics and Gynaecology, Level 3, Women's Centre, John Radcliffe Hospital, Headington, Oxford, OX3 9DU, UK.

E-mail: suseela.yelumalai@obs-gyn.ox.ac.uk celine.jones@obs-gyn.ox.ac.uk kevin.coward@obs-gyn.ox.ac.uk

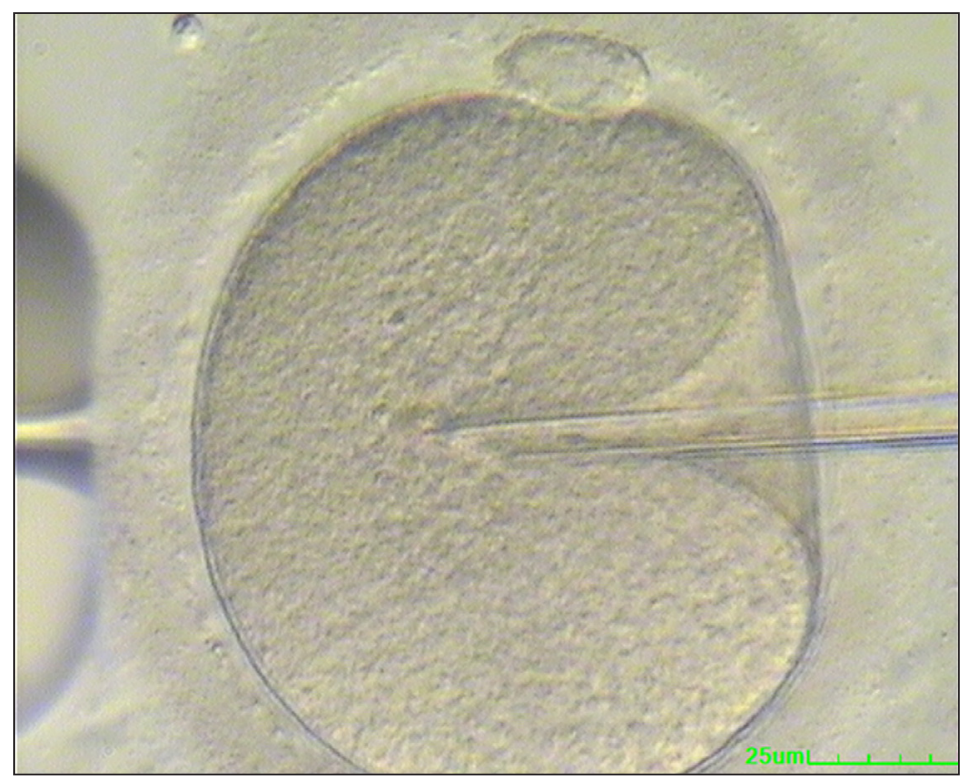

Intracytoplasmic sperm injection (ICSI) in which a single human sperm is directly microinjected into a human oocyte. The individual sperm can be seen towards the sharp end of the glass micropipette about to be transferred into the oocyte cytoplasm. Image courtesy of Tracey Griffiths (Oxford Fertility Unit)

\begin{abstract}
Assisted Reproductive Technology (ART) is a suite of laboratory techniques designed to rescue infertile phenotypes. While ART has led to the birth of 5 million ART babies worldwide, success rates rarely exceed $40 \%$. One potential factor for this could be iatrogenic ('clinician-induced') damage to critical sperm proteins, such as phospholipase C zeta (PLC) and protamine, which are fundamental for oocyte activation and sperm DNA integrity, respectively. This report describes how we have begun to investigate the adverse effects of ART techniques upon these key sperm proteins. We also describe the pathway taken by Miss Suseela Yelumalai to acquire a scholarship from the Malaysian Government and her postgraduate experience at the University of Oxford. We introduce the facilities and learning opportunities available at the Institute of Reproductive Sciences (IRS) which houses Dr Kevin Coward's research laboratory, and finally, highlight the potential for collaborative development between the Universities of Oxford and Malaya.
\end{abstract}

Keywords: Assisted reproductive technology, iatrogenic damage, phospholipase c zeta, protamine 


\section{Introduction}

The prevalence of human infertility is growing rapidly and is currently estimated to affect at least 1 in 4 couples (1). Such worrying statistics have led to the rapid expansion of Assisted Reproductive Technology (ART), a sophisticated suite of techniques used to rescue human infertility under controlled laboratory environments. Thus far, ART has resulted in the birth of over 5 million babies worldwide (2) and continues to attract significant financial investment. Techniques deployed in the ART laboratory are becoming increasingly more sophisticated and involve the treatment and manipulation of male and female gametes under artificial conditions. One pioneering technique, for example, is intracytoplasmic sperm injection (ICSI), in which a single pre-selected sperm is microinjected directly into an oocyte. However, for a variety of factors, the success rate of ART rarely exceeds $40 \%$ (3), meaning that in most cases, ART is likely to fail. It is therefore imperative that scientific research strives to identify the causative factors involved such that patients continue to be provided with the best levels of clinical care. The causes of poor success in ART are highly likely to be multi-factorial in nature, and can be generally attributed to factors related to the sperm, oocyte, laboratory environment, and the technical ability of the clinical embryologists involved. Above all, ART attempts to recreate a very specialized interactive encounter between two very specialized haploid cells (the sperm and oocyte) in an artificial environment in such a manner that the oocyte is fertilized and activated to begin dividing into an embryo. Protecting the health and functional ability of the two gametes involved, and recreating the environmental conditions in which the gametes would ordinarily meet, are particularly difficult, and likely to be a major factor underlying poor success rates.

However, one particular factor that has only recently drawn attention from the research community is the increasing risk of iatrogenic ('clinician-induced') damage being inadvertently caused to gametes during ART procedures. Such damage may, for example, be caused by washing, selection, or manipulative procedures in the laboratory environment, and induce structural or functional deficiencies in sperm or oocytes (4). Consequently, identifying which techniques may be at fault, and determining how iatrogenic damage arises and manifests, is of great importance. The Coward Laboratory at the Nuffield Department of Obstetrics and Gynaecology, University of Oxford, has been investigating such issues since 2010, particularly with respect to how ART techniques may influence critical sperm proteins that play a fundamental role in sperm structure and function. In 2011, the Coward Laboratory published disturbing data showing that cryopreservation, a routine technique used in ART to store human sperm, could cause significant reductions in the levels of phospholipase C zeta (PLCZ), a protein that is responsible for activating the oocyte at fertilization (5). This implies that human sperm that have undergone freeze-thaw cycles may exhibit deficiency in their ability to induce oocyte activation (3). Current work in the laboratory seeks to investigate the effects of other routine ART techniques used to treat, select, or manipulate human sperm, upon key sperm proteins such as PLCZ, and more recently, the protamine family, which plays a fundamental role in maintaining DNA integrity in the sperm nucleus (6). Such research should lead to the modification or replacement of techniques and equipment, or lead to changes in environmental laboratory conditions, such that patients are provided with the best chances of success.

This article describes firstly, how Miss Suseela Yelumalai secured funding from Malaysian resources to join the Coward Laboratory in 2011 to take part in this pioneering field of research, and secondly, how her return to the University of Malaya in 2014 should result in the initiation of a long-lasting and fruitful research collaboration between the Universities of Oxford and Malaya.

\section{The route from Malaysia to the University of Oxford}

Miss Suseela Yelumalai graduated in 2011 with a Master's degree in Medical Sciences from the Department of Obstetrics and Gynaecology, University of Malaya, Malaysia, under the supervision of Professor Siti Zawiah Omar. In testament to her academic performance and motivation, and with the welcome support of the Vice Chancellor of the University of Malaya, Tan Sri Ghauth Jasmon, Suseela was offered two prestigious scholarships for academic study overseas leading to the award of a PhD. Suseela secured funding from the Bright Sparks scheme at the University of Malaya, and received a Skim Latihan Akademik Institusi Pengajian Tinggi (SLAI) Fellowship from the Ministry of Higher Education (MOHE) in Malaysia. After many hours searching the internet and online scientific literature databases, Suseela became increasingly drawn to the work of Dr Kevin Coward at the University of Oxford, and approached him directly by email to enquire about the possibility of registering for a postgraduate research degree under his supervision. Following numerous emails and an online interview via Skype, Suseela was offered the chance of joining Dr Coward's Laboratory for a three year period leading to the eventual award of a PhD.

Suseela joined Dr Coward's team in November 2011 and received significant help and support to help her acclimatize into her new social and academic environment. Like Dr Coward, Suseela is affiliated to the Nuffield Department of Obstetrics and Gynaecology (NDOG), one of the largest academic Obstetrics and Gynaecology departments in the UK (www.obs-gyn.ox.ac.uk). She will shortly begin her third and final year of study and has enjoyed her time in Oxford immensely. Her research focusses upon how iatrogenic damage incurred during routine ART may influence the abundance, expression and degradation of $\mathrm{PLC} \zeta$ and protamine, sperm proteins that play a critical role in oocyte activation and DNA integrity, respectively. She has already published various aspects of her work $(4,7,8)$ and is preparing several other research papers for 
publication. She has also presented her work at a variety of national and international conferences, and will shortly be delivering an oral presentation at the annual meeting of the American Society for Reproductive Medicine in Boston, USA. Suseela has also been selected as the NDOG student representative for the Joint Consultative Committee for the Medical Sciences Division (which oversees issues and problems associated with postgraduate taught and research degrees), and the NDOG Athena Swann working group (which promotes equality and enhanced working environments in academia). In addition, she has been chosen by the NDOG to give a short talk of her experiences as an Oxford PhD student to an audience of over 200 incoming postgraduate students at the Medical Sciences Division 'Red Carpet' Event in October 2013.

\section{The Coward Laboratory}

Dr Kevin Coward graduated from the University of Stirling in Scotland with a B.Sc. (Hons) in Biological Science and a PhD in Reproductive Physiology and Endocrinology. He held Post-Doctoral Fellowships at Brunel University, Queen Mary University London, Imperial College London, and University College London. In 2002, he joined the Department of Pharmacology, University of Oxford, as a Senior Research Fellow, to investigate oocyte activation and calcium signaling at fertilization. In 2008, he moved to the NDOG as Director of the new M.Sc. in Clinical Embryology (a course which he designed and implemented; www. obs-gyn.ox.ac.uk/MSc), and as a Principal Investigator (http://www.obs-gyn.ox.ac.uk/research/kevin-coward/). $\mathrm{He}$ is also a Fellow of the Higher Education Academy, an organization devoted to excellence in teaching and learning. His research focuses upon oocyte activation, male factor infertility, iatrogenic damage incurred during ART, and the development of nanoparticle-mediated delivery systems to deliver research tools and clinical agents to mammalian gametes and embryos. He has published over 70 peer-reviewed articles in international journals and contributed over 70 abstracts, posters, and oral presentations to scientific conferences. In less than five years of forming his own independent research group, he has published 32 papers. The Coward Laboratory is a friendly and highly motivated research group, managed on a day-to-day basis by Mrs Celine Jones, who has worked in the NDOG for almost nine years. Celine joined the Coward Laboratory in 2008 and is jointly responsible for the MSc in Clinical Embryology. Kevin and Celine take great pride in their enthusiastic and motivated approach to teaching and research. They were awarded a Major Educator Teaching Excellence Award in 2012 for the development of the MSc in Clinical Embryology, and an OxTalent Award in 2013 for their innovative use of information technology in postgraduate teaching. The Coward Laboratory has also won several academic prizes for their research. At the time of writing, the Coward Laboratory is composed of nine personnel: Kevin, Celine, two PhD students, four MSc students, and an undergraduate medical student.

\section{The working environment: The Institute of Reproductive Sciences}

The efficiency and quality of the research and teaching carried out by the Coward Laboratory relies heavily upon the Institute of Reproductive Sciences (IRS), within which the Laboratory is housed. Opening in 2009, the IRS represents a collaborative venture between the University of Oxford (NDOG), the Oxford Fertility Unit (OFU), and Reprogenetics, UK. Collectively, this partnership creates a unique environment in which clinical diagnostics, treatment, genetic diagnosis, clinical and basic research, and postgraduate education, all occur under the one roof. The IRS provides the Coward Laboratory with state-of-theart teaching and research facilities (Figure 1), fuelled by research collaboration with OFU clinicians, embryologists, and nurses.

\section{The Oxford experience}

Since her arrival in Oxford, Suseela has been introduced to a wealth of scientific techniques in reproductive science and ART, including the ethical use of human semen samples. For example, semen analysis is a routine protocol in ART units. In the Coward Laboratory, we use Computer Assisted Sperm Analysis to investigate basic sperm parameters such as progressive motility, concentration and sperm velocity distribution. Training was provided in the use of this sophisticated system for the analysis of human, mouse, boar and rat sperm. Other key techniques include sperm washing and selection techniques, cryopreservation, sperm DNA fragmentation assessment, and immunofluorescent determination of target protein expression and localization in sperm samples by fluorescent and confocal microscopy (Figure 2). Many other techniques are available within the Coward Laboratory including recombinant DNA technology, polymerase chain reaction (PCR), recombinant protein expression and purification, bioinformatics, nanotechnology, gamete micromanipulation, and the use of infra-red laser to biopsy embryos for genetic assessment. While focusing predominantly upon human samples acquired from the OFU and other overseas collaborators, the Laboratory also utilizes several animal models including the mouse, boar, rat, cow, and zebrafish, to inform both their research and teaching obligations. A key role of the Laboratory is to help diagnose cases of oocyte activation deficiency in infertile males attending the OFU. As part of her doctoral studies, Suseela carries out numerous research investigations upon sperm samples from infertile patients

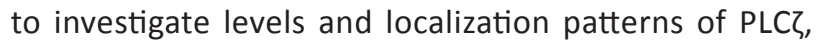
and in doing so, can provide OFU clinicians with valuable information relating to the oocyte activation ability of such sperm. By virtue of her research, Suseela already plays a key role in pioneering attempts to diagnose and treat oocyte activation deficiency in humans, a condition that affects approximately 1200 cases annually in the UK alone. Her broad training in the biochemical and molecular techniques used to study sperm function in humans and a variety of animal models, and in the treatment, selection 

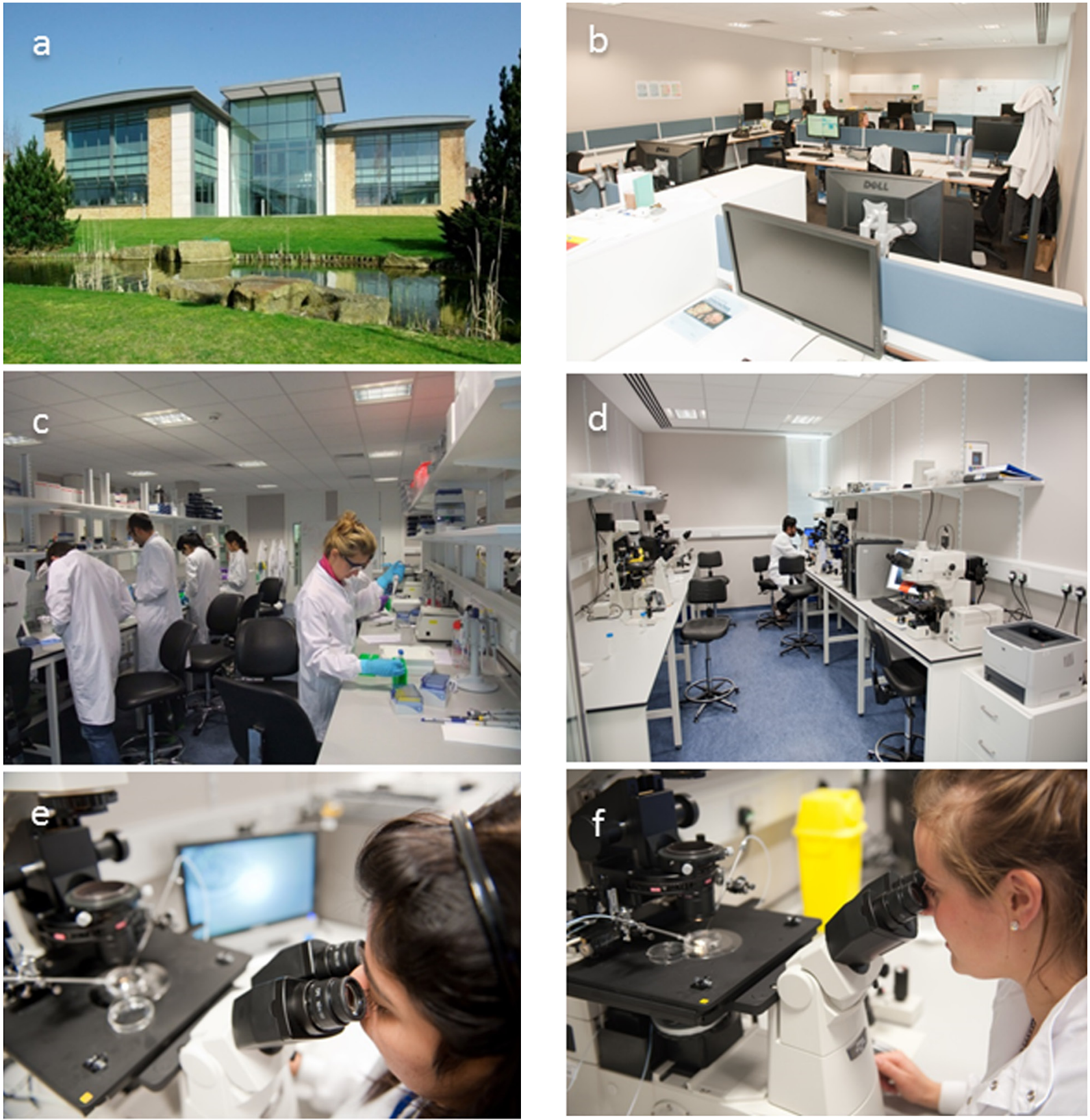

Figure 1: Images of (a) the Institute of Reproductive Sciences (IRS), (b) the postgraduate study room within the IRS, (c) the teaching laboratory for the MSc in Clinical Embryology, (d) the micromanipulation suite, and $(e) /(f)$ students performing micromanipulation procedures. Image courtesy of Matt Lodge.

and manipulation techniques used in ART, creates a solid foundation from which to build an independent career upon her return to Malaysia. After just six months in the Coward Laboratory, Suseela was awarded with a prestigious Oxford Travel grant which allowed her to spend two weeks at the University of Murcia in Spain, alongside Professor Joaquin Gadea, one of Dr Coward's collaborators. During this time, Suseela worked in a veterinary department carrying out a preliminary investigation of how the technique of in vitro maturation might influence the expression of key proteins in porcine and bovine oocytes that are involved in the oocyte activation mechanism.
A key goal of the Coward Laboratory is to provide their students with the necessary experience to succeed as an independent academic. Consequently, Suseela meets regularly with Dr Coward to discuss research and career development opportunities, and has supervised four under- and post-graduate research students thus far. She has also received dedicated teaching skills training via the University of Oxford, and will be delivering teaching on the MSc in Clinical Embryology over the next few months. Her approach to teaching and research has matured enormously during her time in Oxford, most notably in terms of her confidence and resourcefulness. 

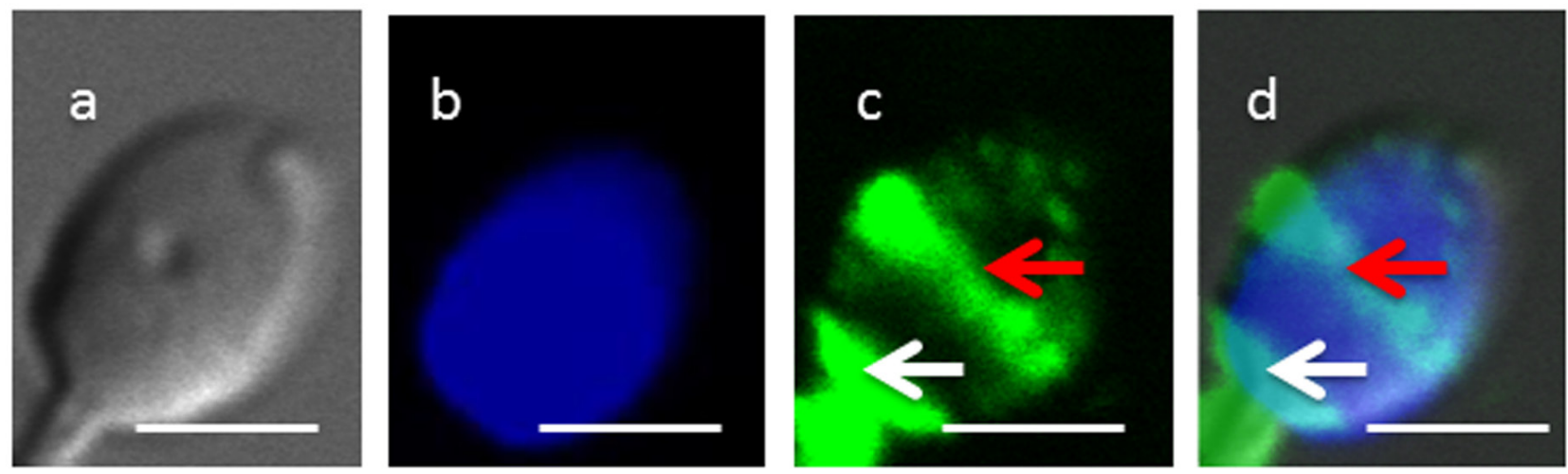

Figure 2: Confocal microscope images of fertile human sperm showing (a) differential interference contrast image, (b) nuclei, (c) phospholipase C zeta (PLCZ), the protein responsible for activing the oocyte at fertiisation, and (d) an overlay showing

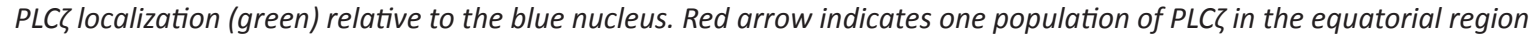
of the sperm head, whereas the white arrow indicates a second population in the post-acrosomal region. Scale bar represents a distance of $5 \mu \mathrm{m}$. Image courtesy of Suseela Yelumalai.

Suseela has also received dedicated training in statistics, oral presentation skills, information technology, and academic writing skills, via the Medical Sciences Division at the University of Oxford. Such aspects of professional development are considered critical in creating a future academic capable of both carrying out informed and rigorous scientific experiments, and in communicating data and ideas to others via teaching or research presentations.

\section{Future prospects and collaboration}

The expected date for completion of Suseela's PhD is September 2014. The Ministry of Higher Education (MOHE) and University of Malaya (UM) will thus welcome Suseela's return to Malaysia in October 2014. Upon arrival, as a qualified reproductive scientist, Suseela is expected to become a Lecturer to carry out research and teach under- and post-graduates in the Faculty of Medicine. Suseela's over-riding ambition is to establish a motivated research group within the Department of Obstetrics and Gynaecology, based upon the skills and experiences she acquired during her time in the Coward Laboratory at the University of Oxford. Her fundamental goals are to pursue academic excellence and to follow Dr Coward's example in trying to inspire and motivate a friendly but highly rigorous and effective research group with clear values, principles, and integrity. Her aims are to expand upon her doctoral work by creating links with academic and clinical units both within and beyond the University of Malaya, and by maintaining active collaborative links with the Coward Laboratory in Oxford. It is hoped that such collaboration will lead to the regular exchange of students between the Universities of Malaya and Oxford, and involve key members of the Coward Laboratory spending time at the University of Malaya to contribute to teaching programs, and to initiate new research projects and other collaborative ventures (Figure $\mathbf{3}$ ). Considering the prevalence of infertility in Malaysia and the increasing number of couples seeking fertility treatment at the University of Malaya Medical Centre (UMMC), such collaborative links would enhance levels of clinical/ laboratory care, thus providing an excellent opportunity for the University of Malaya to establish a ground-breaking research centre for excellence in reproductive biomedicine.

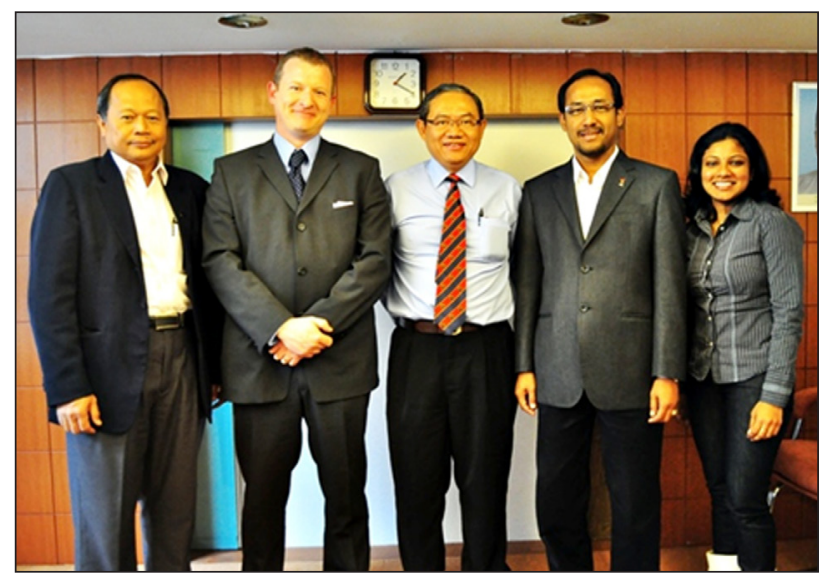

Figure 3: The University of Malaya Vice Chancellor's visit to the Malaysian High Commission, London, in May 2012. From left: Professor Dato Dr. Mohd Sofian Azirun (Dean of Faculty Science, University Malaya), Dr Kevin Coward, Tan Sri Ghauth Jasmon (Vice Chancellor of the University Malaya) Dr. Mohd Anizu Hj. Mohd Nor (Director, Education Malaysia, London), and Miss Suseela Yelumalai.

\section{Further correspondence}

For general enquiries, contact Miss Suseela Yelumalai (Email: suseela.yelumalai@obs-gyn.ox.ac.uk). For information relating to the MSc in Clinical Embryology, PhD opportunities in Oxford, or enquiries regarding collaborative research, please contact Dr Kevin Coward (Email: kevin.coward@obs-gyn.ox.ac.uk). 


\section{Acknowledgement}

The authors wish to thank the Nuffield Department of Obstetrics and Gynaecology (NDOG), University of Oxford, for their financial contribution to this project. We would also like to thank the Bright Spark Scholarship Scheme from the University of Malaya, and the Ministry of Higher Education (MOHE), Malaysia, for providing the necessary funding for Miss Yelumalai to pursue her PhD studies under Dr Coward's supervision.

\section{References}

1. Mascarenhas MN, Flaxman SR, Boerma T, Vanderpoel S, Stevens GA. National, regional, and global trends in infertility prevalence since 1990: a systematic analysis of 277 health surveys. Plos Med 2012; 9: e1001356.

2. Human Fertilisation and Embryology Authority [http:// www.hfea.gov.uk/]. London: Human Fertilisation and Embryology Authority; 2013. [Updated 2013 Aug 12; cited 2013 Sep 2 ]. Available from: http://www/hfea. gov.uk/ivf-figures-2006.html.

3. Kashir J, Heynen A, Jones C, Durrans C, Craig J, Gadea J, et al. Effects of cryopreservation and density-gradient washing on phospholipase $\mathrm{C}$ zeta concentrations in human spermatozoa. Reprod Biomed Online 2011; 23: 263-7.
4. Yelumalai S, Kashir J, Jones C, Bagheri H, Oo SL, McLaren L, et al. Clinician-induced (iatrogenic) damage incurred during human infertility treatment: Detrimental effects of sperm selection methodd and cryopreservation upon viability, DNA intergrity, and function of human sperm. Asian Pac J Reprod 2012; 1: 69-75.

5. Amdani SN, Jones C, Coward K. Phospholipase C zeta (PLCzeta): Oocyte activation and clinical links to male factor infertility. Adv Biol Regul. 2013; July 17: doi:pii:S2212-4926(13)00054-7.

6. Kanippayoor RL, Alpern JH, Moehring AJ. Protamines and spermatogenesis in Drosophila and Homosapiens: A comparative analysis. Spermatogenesis 2013; 3: e24376.

7. Jones C, Bagheri H, Kashir J, McLaren L, Yelumalai $S$, Coward K. The potential effect of clinicianinduced (iatrogenic) damage incurred during fertility treatment upon gamete competence and embryonic viability. In: Nascimento R, Vilas Boas H, editors. Infertility. Genetic Factors, Treatment Risks and Benefits, Social and Psychological Consequences. New York: Nova Science Publishers; 2013.p.77-94.

8. Kashir J, Yelumalai S, Jones C, Coward K. Clinicianinduced (iatrogenic) damage incurred during human fertility treatment: detrimental effects upon gamete and embryo viability and the potential for epigenetic risk. Human Genet Embryol 2012; 2:e105. 